\title{
La autonomía del paciente en la práctica clínica
}

\author{
Patient's autonomy in clinical practice
}

El concepto de autonomía es un elemento esencial para comprender los profundos cambios de la relación médico-paciente, o más claramente de la relación clínica, en las últimas décadas. En su origen la autonomía (del griego auto = uno mismo, y nomos = norma) es un concepto propuesto por Kant en el siglo 18, quien concibe al ser humano como un sujeto moral capaz de decidir desde su razón y libertad, que es responsable de sus actos, y quien debe ser respetado como tal. Se refiere al ser humano en abstracto más que a alguien que decide cosas concretas en condiciones particulares. En el ámbito de la Bioética la autonomía presupone la competencia o capacidad de decisión en condiciones de racionalidad, información, comprensión y libertad para aceptar tratamientos o para participar en una investigación.

La Bioética ha propuesto entre sus principios el de Autonomía, el que ha pasado a ser en general más relevante que los principios de Justicia, No Maleficencia y Beneficencia. Sin embargo, el derecho de las personas a "consentir" las intervenciones sobre su propio cuerpo ya había sido reconocido por el juez Cardoso en 1914. Posteriormente el juez Bray en 1957 estableció el deber de entregar la información necesaria para decidir. Se unieron así las perspectivas éticas y jurídicas que dieron origen al Consentimiento Informado como forma de respeto al derecho de las personas a ejercer su autonomía para aceptar o rechazar intervenciones o tratamientos. Sin embargo, la capacidad de cada persona para actuar autónomamente es variable por razones culturales, educacionales o emocionales, lo cual impone a los profesionales el deber de respetar la autonomía de sus pacientes, junto a la necesidad de ayudarlos a tomar decisiones en salud.

El fundamento del consentimiento informado es por lo tanto la obligación moral de respetar las decisiones autónomas de los pacientes, para procurar así su mayor bien de acuerdo a su propio proyecto vital. Se asocia generalmente el consentimiento informado al principio de Autonomía, pero este principio va necesariamente acompañado del principio de Beneficencia y ambos se fundamentan en la dignidad y en la libertad de las personas. El consentimiento informado se convierte así en un derecho de los pacientes y en un deber de los médicos ${ }^{1}$.

En los modelos de relación médico paciente descritos por E. Emanuel se distinguen el antiguo modelo paternalista, reemplazado por un modelo informativo en el cual el médico informa como un experto para que el paciente decida de manera autónoma. Estos extremos se combinan y complementan en los modelos interpretativo y deliberativo que se concretan en una propuesta de decisiones compartidas que considera que el paciente tiene derecho a decidir, reconociendo que su capacidad para comprender y analizar la información es limitada y variable en cada situación concreta. Por otra parte, solo el paciente puede determinar qué es lo mejor para él de acuerdo con sus valores y preferencias. Sin embargo, si el consentimiento informado se concreta solo en formularios firmados con limitada comprensión de los pacientes, lo que de hecho ocurre es una medicina paternalista con documentos de consentimiento "firmado" más que informado. Lo anterior lleva a la necesidad de distinguir entre el proceso y los formularios de consentimiento informado. El centro de los procesos de decisión en la práctica clínica debe estar en esta relación de ayuda más que en el consentimiento informado ${ }^{2}$.

En la práctica clínica el consentimiento informado se ha transformado en un trámite administrativo más, solicitado al paciente para cada intervención o procedimiento y pidiendo su firma muchas veces casi inmediatamente antes de su realización. Hay poca preocupación por la información y comprensión de la misma por el paciente, y el número de documentos a firmar resulta excesivo e innecesario porque cada servicio o especialidad tiene sus propios formularios. Muchos consideran erróneamente 
estos formularios como un recurso defensivo ante eventuales reclamos o demandas, mientras otros los solicitan solo para cumplir con obligaciones burocráticas.

Es necesario reencontrar el verdadero sentido del consentimiento informado, basado en el respeto a la decisión debidamente fundada de los pacientes, de tal manera que tanto el proceso como su documentación o registro tengan el mismo sentido y propósito. El proceso y el registro por el cual cada paciente manifiesta su aprobación o consentimiento tiene elementos básicos para que pueda ser considerado éticamente válido. Estos elementos son: 1) Proceso de diálogo entre un profesional que informa y un paciente que acepta o no un procedimiento o tratamiento; 2) Voluntariedad, lo cual implica que el paciente no sea presionado a la firma del consentimiento como requisito para su tratamiento; 3) Información según la competencia del paciente, de tal manera que la comprensión sea lo central por sobre la cantidad de información; 4) Competencia o capacidad de decisión del paciente, lo cual en muchos casos es complejo de determinar dada su variación por edad, nivel educacional, estado emocional o salud mental; 5) Si el paciente está impedido para decidir deberá hacerlo quien legítimamente lo representa, lo cual son los padres por sus hijos menores, los cónyuges entre ellos, y los hijos u otros familiares por los adultos mayores. Finalmente, solo si los cinco elementos descritos se cumplen cabalmente corresponde firmar un documento o registro que certifica que el paciente o su subrogante otorgan su acuerdo o autorización para que se realice un tratamiento o procedimiento.

Generalmente se habla de autonomía como un concepto abstracto, como un derecho, como un concepto jurídico o como una cualidad que se tiene o no se tiene. Sin embargo, como ya se ha planteado, lo importante es comprender la autonomía encarnada en una persona que sufre por una enfermedad $y$ quien además debe, en estas condiciones, decidir su aceptación o rechazo a un tratamiento. Como es frecuente que el paciente comprende de manera insuficiente, los profesionales necesitan conocerlo bien para poder favorecer y respetar su autonomía en cada decisión concreta. Por esta razón, el modelo paternalista de relación médico paciente que desconoce la autonomía del paciente, o el modelo autonomista que delega toda la decisión en el paciente, deben dar paso a formas de decisiones compartidas. Este modelo es el de una relación en la cual el médico informa al paciente de manera comprensible y a la vez le ayuda a decidir o a otorgar su consentimiento, sin guiarlo de manera paternalista.

Resulta necesario preguntarse para qué actos médicos se requiere el consentimiento informado. Si se piensa como una forma de participación o aceptación del paciente en las decisiones, la respuesta es que es necesario siempre. Pero si se plantea la pregunta de cuando se requiere un proceso formal con información escrita y formularios firmados, la respuesta es que es más necesario mientras mayor sea el riesgo de una intervención, más alternativas existan y menor sea el beneficio esperado. Será entonces menos necesario mientras menores sean los riesgos de una intervención, menos alternativas existan y mayores sean los beneficios esperados. En la práctica los procesos de consentimiento informado, incluyendo información y registro en documentos o formularios, son necesarios antes de intervenciones quirúrgicas, tratamientos o procedimientos diagnósticos invasivos, intervenciones de alta complejidad, ingreso a cuidados intensivos, y también para decisiones de abstención, rechazo o retiro de tratamientos.

El desafio es encontrar formas para optimizar estos procesos de acuerdo a la esencia del consentimiento informado como un derecho del paciente a ejercer su autonomía, y al deber del médico de informar y ayudarle a tomar sus decisiones. Esto compromete de alguna manera a todos los involucrados en los procesos de decisión y de consentimiento informado. En otras palabras, significa lograr que los pacientes tengan claro su derecho y sus limitaciones para decidir y para consentir, que los médicos y otros profesionales comprendan el sentido del consentimiento informado y su deber de informar de manera veraz y comprensible los tratamientos que proponen. A lo anterior es necesario agregar que las instituciones y sus directivos, auditores y abogados, comprendan el consentimiento informado como un proceso compartido de decisiones que, para algunos tratamientos o procedimientos, se registra en documentos firmados por los pacientes o por sus representantes ${ }^{3,4}$.

Como respuesta a la mencionada deformación del consentimiento informado, se han planteado cambios sustanciales en los procesos de decisión. Algunas propuestas buscan transformar los formularios en estrategias diferentes. Una de ellas, del Royal College of Surgeons en el Reino Unido propone un 
procedimiento de Request for Treatment, proceso en el cual el paciente solicita su tratamiento después de estudiar las alternativas, y el médico es quien firma aceptando su ejecución. De esta manera el paciente es el centro de la decisión, más allá de ser alguien quien firma un formulario como requisito para el tratamiento. Otras alternativas en desarrollo son nuevas maneras de informar utilizando medios digitales o impresos diseñados para la mejor comprensión de los procedimientos por parte del paciente. Son los denominados Decision Aids, entendidos como formas de apoyo al paciente para mejorar su decisión. Los pacientes que han decidido con estas formas de apoyo han destacado sentirse más conocedores del tema, más respetados en sus valores y más participativos en la decisión tomada.

A modo de conclusión, se plantea que en la práctica clínica los formularios de consentimiento informado en uso no constituyen una forma apropiada de comunicación y decisión, ni demuestran que estos procesos se han realizado de manera válida. Son más bien formularios para la firma de pacientes, redactados por profesionales de la salud o por autoridades institucionales. Estos documentos son muy variados, tienen formalidades diversas, no son exigencias legales y en su mayoría no son por sí mismos un verdadero consentimiento informado. Son constancias formales de que el paciente o su subrogante ha otorgado su consentimiento, aunque sabemos que las más de las veces es solo un formulismo para cumplir con exigencias normativas. Por esta razón, se invita a los lectores a un análisis crítico y a un camino creativo para lograr que el consentimiento informado sea una manera de ayudar a procesos de decisiones compartidas entre profesionales y pacientes, a quienes se respeta auténticamente su autonomía.

Dr. Juan Pablo Beca Infante

Profesor titular de Medicina,

Director del Magíster Interuniversitario de Bioética, Facultad de Medicina Clínica Alemana-Universidad del Desarrollo, Miembro Honorario de la Academia Chilena de Medicina Email:jpbeca@udd.cl

\section{Bibliografía}

1. SIMON P. Diez mitos en torno al consentimiento informado. An Sist Sanit Navar 2006; 29 (Supl. 3): 29-40.

2. SHAW D, ELGER B. Evidence-Based Persuasion: An Ethical Imperative. JAMA 2013; 309: 1689-90.

3. KRUMHOLZ HM. Informed consent to promote patient-centered care. JAMA 2010; 303:1190-1.
4. BRAITHWAITE RS, CAPLAN A. Does patient-centered care mean that informed consent is necessary for clinical performance measures? J Gen Intern Med 2014; 29: 558-9.

5. SPATZ ES, KRUMHOLZ HM, MOULTON BA. The New Era of Informed Consent Getting to a ReasonablePatient Standard Through Shared Decision Making. JAMA 2016; 315: 2063-4. 